Eleştirel Derleme / Review Paper

\title{
Yeraltı Suları Bütçesi Tartışmaları
}

\author{
Groundwater Budget Discussions
}

Muhterem DEMİROĞLU

ITÜ Maden Fakültesi Jeoloji Müh. Bölümü, Maslak, ISTANBUL

\section{ÖZ}

Yeraltı suları bilançosu, belirli bir zaman aralığında dengede olduğu kabul edilen herhangi bir akifere giren ve çıkan suyun, depolanmadaki değişimi de dikkate alınarak, eşit olması prensibine dayanır. Kısa sürede yenilenebilen yüzey suları bilançoları doğrudan güncel beslenim ve boşalımla ilişkilidir. Yeraltı sularında derin dolaşımlı hatta farklı iklim koşullarında sisteme giren ve çıkan değişik yaşlardaki sular, beslenim boşalım eşitliğini karmaşık hale getirir. Beslenim, boşalım değişikliğiyle ilgili geleceği de kapsayan hesaplamalar, yeraltı suyu bütçesi olarak adlandırılır. 1950’li yıllara kadar sürdürülebilir yeraltı suyu yönetimi, "Yeraltı suyu çekimi doğal beslenimi aşmamalıdır." kabulü ile yapılmıştır. DSİ tarafından halen yeraltı suyu işletme sahaları izinleri aynı yaklaşımla verilmektedir. 1980'li yıllardan sonra bu yaklaşımın efsane olduğu ilan edilmiş, boşalım ve beslenimden alıkonan suların hesaplanması giderek beslenimi göz ardı eden bir yaklaşımı gündeme getirmiştir. Doğru yaklaşım ise sürdürülebilir yeraltı suları çekiminde doğal beslenimin yanında, boşalımdan alıkonan ve beslenim artışlarını dikkate alan yaklaşımdır. Sürdürülebilir yeraltı suları çekiminde kuyu yerleri boşalımdan alıkonan ve beslenim artışlarını dikkate alan yaklaşımla seçilmelidir. Her sene çekilen yeraltı suyu miktarıyla yıllık beslenim miktarı arasında uzun süreli bir denge kurulması ve boşalımdan alıkonan su miktarı gelecekte oluşacak çevre etkisi dikkate alınarak belirlenmelidir. Bu çalışma ile tartışmalar değerlendirilerek, yeraltı suları bütçesi ve modelleme çalışmalarında ihmal edilen ayrıntılar vurgulanmıştır.

Anahtar kelimeler: Akifer, Beslenim, Boşalım, Yeraltı Suları Bütçesi.

\section{ABSTRACT}

The groundwater balance is based on the principle that the water entering and leaving any aquifer considered to be equal over a certain time interval, taking into account the change in the storage. Groundwater, a renewable resource, is quite complicated in its balances, as the equilibrium conditions take place in very long periods. Surface waters are directly related to current recharge and discharge, while circulating groundwater, is in a different age and even in different climatic conditions in the system and complicate this relationship. Accountings of all the inflows, outflows, and including changes in the future, are called a groundwater budget. Sustainable groundwater management until the 1950s was made with the understanding that the groundwater discharge should not exceed the natural recharge and the permission for groundwater withdrawal is still given by State Hydraulic Works (DSI) with the same approach. Since the 1980s, this approach has been declared legendary, and the calculation of water retained 
Demiroğlu

from discharge and recharge has come to an approach that ignores the recharge. The truth is an approach that takes into account the decreased discharge and increased recharge in addition to recharge. For a sustainable groundwater development, the well locations should be selected with an approach that takes into account the increased recharge and decreased discharge. The rate of groundwater removal should be defined by the long-term balance between recharge and discharge, and the capture rate from discharge must be defined by taking into account the long-term environmental impacts. With this study, discussions were evaluated and the importance of the groundwater budget was emphasized in sustainable groundwater management.

Keywords: Aquifer, Recharge, Discharge, Groundwater Budget.

\section{GİRİ̧}

Akifer olarak adlandırılan, yeraltı suyunu boşluk ya da kırık çatlaklarında depolama ve iletebilme özelliğinde olan kayaçlar, ayrı ayrı su kütlelerini oluştururlar. Sular yağışla, hareket halindeki su kütlesine sürekli eklenir (beslenir) ve sürekli ayrılır (boşalır). Yeraltı suyunun beslenimi yağıştan (yağmur, kar, çiğ vb.), yüzey sularından, komşu akiferlerden, sulamadan dönen sulardan, suni beslenmeden ve şebeke kayıplarından eklenen sularla gerçekleşir (Freeze ve Cherry, 1979; Alley vd., 1999; Dumlu, 2005; Aksever, 2012). Yeraltı suyu boşalımı ise buharlaşmaterleme, komşu akiferlere sızma, akarsulara boşalım, kuyu, drenaj, kanal ve benzeri yollarla yapılan yapay çekimler şeklindedir.

Akiferlerdeki tüm girişler, çıkışlar ve değişikliklerle ilgili geleceği de kapsayan hesaplamalar, yeraltı suyu bütçesi olarak adlandırılır. Belirli bir zaman aralığında dengede olduğu kabul edilen herhangi bir akifere giren ve çıkan su, depolanmadaki değişim de dikkate alınarak, eşit kabul edilir (Çizelge 1).

Küresel bazda, yüzey suyu her 9 ile 16 günde bir, ortalama 11 günde, yenilenir (Korzoun vd., 1978; L’vovich, 1979; Ponce vd., 2000). Yüzey suları bilançoları güncel beslenim ve boşalımla ilişkilidir. Yeraltı suyu dönüş hızı, akiferin türü, derinliği ve hidrolik iletkenlik özelliklerine bağlı olarak, günler, yüzyıllar, bin yıllar arasında değișebilir (Şekil 1). Yeraltı sularının yenilenmesi için ortalama süre 1400 yıldır (Ponce vd., 2000). Aynı akifer sisteminde yavaş akış ve hızlı akış koşulları gerçekleşebilmektedir (Atkinson, 1977). Yeraltı suları denge koşulları çok uzun vadelerde gerçekleştiği için yüzey suları bilançolarından daha karmaşıktır.

Çizelge 1. Doğal koşullar altında bir yeraltı suyu sistemine giren ve çıkan olası su kaynakları.

Table 1. Possible sources of water entering and leaving a ground-water system under natural conditions.

\begin{tabular}{ll}
\hline \multicolumn{1}{c}{ Beslenim } & \multicolumn{1}{c}{ Boşalım } \\
\hline Yağıştan doymamış zon boyunca süzülen beslenim & $\begin{array}{l}\text { Dereler, göller, sulak alanlar, tuzlu su kütleleri (koylar, } \\
\text { haliçler veya okyanuslar) ve kaynaklarla boşalım }\end{array}$ \\
$\begin{array}{l}\text { Akarsular, göller ve sulak alanlardan gelen sularla } \\
\text { beslenim }\end{array}$ & $\begin{array}{l}\text { Yeraltı sularının buharlaşma terleme ile boşalımı } \\
\text { Komşu havzalardan gelen beslenim }\end{array}$ \\
\hline
\end{tabular}




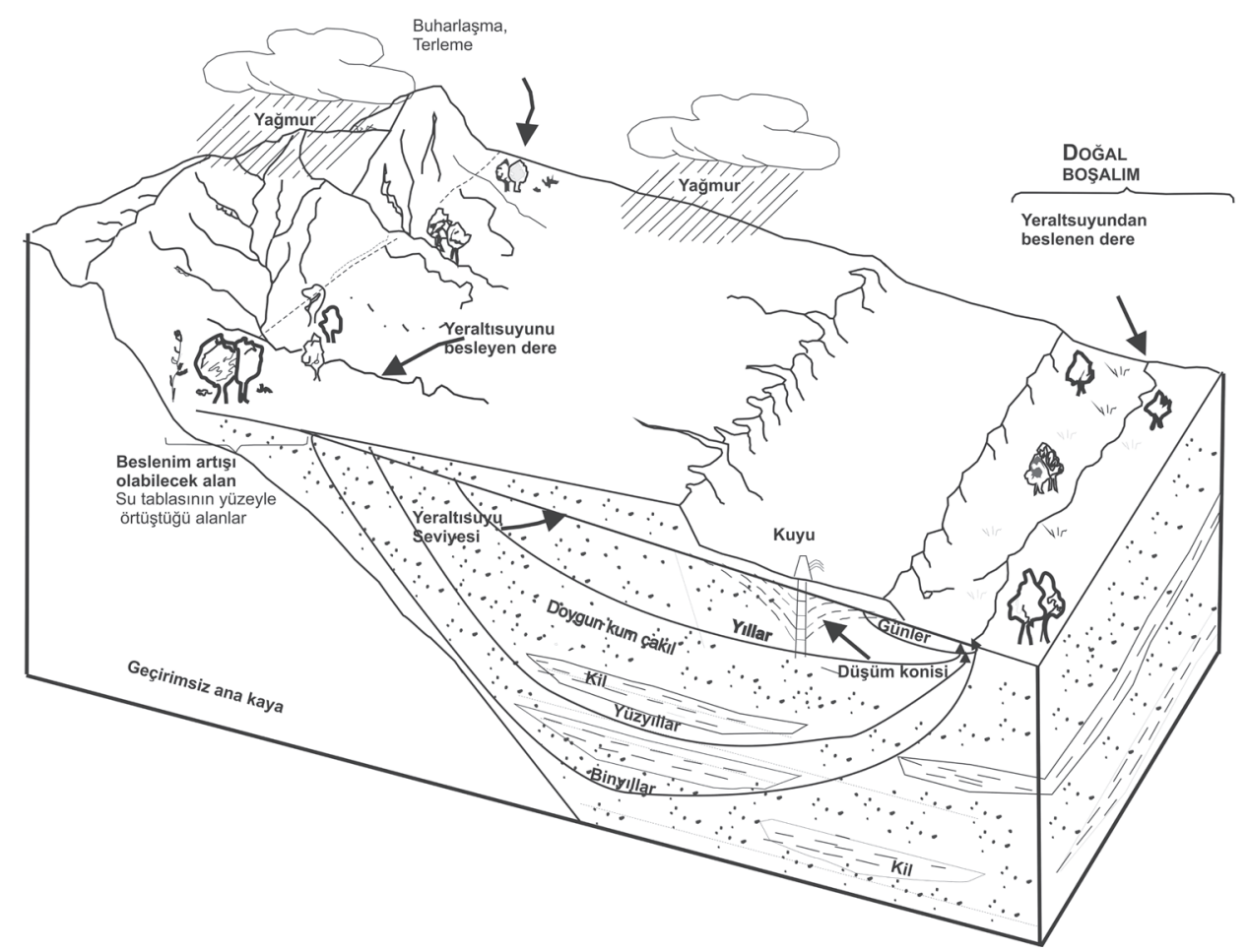

Şekil 1. Kuyularla çekim yapılan bir akiferde beslenim boşalım ilişkisi (Theis, 1940’tan değiştirilmiştir).

Figure 1.Relation of recharge and discharge in an aquifer to discharge by wells (modified from Theis, 1940).

Şekil 1'de Theis (1940) tarafindan oluşturulan sığ dolaşımlı serbest akifere derin dolaşım ilave edilmiştir. Şekilde görüldüğü gibi güncel ve yaşlı sular derede taban akışı oluşturmaktadır.

Bazı hidrojeologlar, bir yeraltı suyu sistemindeki tüketime uygun su miktarını (veya emniyetli verimi), suyun kullanılmaya başlanmadan önceki doğal koşulları dengede varsayarak hesaplamaktadır. Dengedeki sistemde, yeraltı suyu çekimi doğal beslenimi aşmiyorsa "güvenli" olarak kabul edilir (Lee, 1915; Todd, 1959; Muller ve Price, 1979; Alley vd., 1999). 1950'li yıllara kadar sürdürülebilir yeraltı suyu yönetimi, "Yeraltı suyu çekimi doğal beslenimi aşmamalıdır." kabulü ile yapılmıştır. DSİ tarafından yenilenen hidrojeolojik etütlerde yeraltı suyu bütçeleri ve emniyetli verim halen bu yaklaşımla verilmektedir. İlk olarak Theis (1940), bu yaklaşımın maddenin korunumu yasasına uymadığını ve bir akiferden pompajla çekilen suyun mutlaka bir yerlerden eksilmeye karş1lık geldiğini vurgulamıştır (Şekil 1). Kuyu yeri seçimlerinde akiferlerde depolanan suyun tüketilmemesi için:

1-Akifere daha fazla suyun girmesini sağlamak amacıyla yeraltı su seviyesinin yüzeye yakın olduğu alanların seçilmesinin (arttırılan beslenim), 2- Kuyuların, boşalım alanına yakın açılarak sistemden daha az suyun kaçmasının (azaltılan boşalım) sağlanması gerektiği belirtmiştir.

Ancak 1980'li yıllardan sonra, boşalımdan ve beslenimden alıkonan suların hesaplanmas1 için giderek beslenimi gözardı eden bir yaklaşım 
getirilmiştir (Bredehoeft vd., 1982). Bredehoeft (1997) tarafından önerilen yaklaşıma paralel bir yaklaşımla İstanbul-Bakırköy havzası modellenmiştir. Kuyulardan yapay beslenme yapılarak doğal beslenimin ihmal edilmesi durumunda yeraltı su seviyesi değişiminin önemsenmeyecek kadar küçük bir fark yarattığ1 ifade edilmiştir(Tufan, 2007). Bu çalışmada ihmal edilen en önemli ayrıntı, hesaplanan dönemdeki beslenim miktarının çok uzun vadede depolanan yeraltı suları miktarıyla kıyaslanmasıdır.

Sürdürülebilir yeraltı suları çekiminde doğal beslenimin yanında boşalımdan alıkonan ve beslenim artışlarını dikkate alan bir yaklaşım geliştirilmelidir.Ancakbeslenim veya boşalımdan alıkonan sularla akiferde yeni denge koşullarının oluşması ve rezervden çekimin durması için çoğu zaman çok uzun yıllar gerekmektedir. Bredehoeft (1997; 2002)' de açıklanan hidrojeolojik modelle, akiferin iletkenliğine bağlı olarak buharlaşmadan alıkonan sularla dengeye ulaşması için uzun y1llar (100 yıl) gerektiği belirtilmektedir. Alley ve Leake (2004) de verdikleri Nevada Cennet Vadisi Akiferi Modeli ile beslenimin yarısı kadar çekimle bile yeniden dengeli akım koşullarının 300 yıl sonra oluştuğunu göstermişlerdir. Fazla çekim yapılan akiferler, boşalımdan alıkonan sularla rezervden su tüketiminin durması gerçekleşinceye kadar yeniden kazanılamayacak kadar tüketilmiş olabilir (Bredehoeft ve Durbin, 2009).
Ülkemizde Avrupa Birliği, Su Çerçeve Direktifi'ne (2000/60/EC) uyum kapsaminda, Orman ve $\mathrm{Su}$ İşleri Bakanlığı tarafindan, yüzey suları ve yeraltı sularının bütüncül bir yaklaşımla miktar ve kalite açısından korunması için çalışmalar yapılmaktadır. Son olarak yüzeysel suları ve yeraltı sularının izlenmesine dair yönetmelik yayınlanmıştır (T.C. 2014/28910). Bu yönetmelikle, yeralt1 sularının miktar ve kalitesinin mevcut durumunun belirlenmesi ile tabii şartlardan ve insani faaliyetlerden kaynaklanan uzun vadeli değişimlerin değerlendirilmesi ve izlenmesi için Devlet $\mathrm{Su}$ İşleri yetkili kılınmıştır. Devlet Su İşleri tarafindan hidrojeolojik havza etütleri ve modelleme çalışmaları yaptırılmaktadır. Yeraltı suları izleme programları ve ağlarının oluşturulduğu bu dönemde, yeraltı suları bütçesi tartışılmış, modelleme çalışmaları ve değerlendirilmelerinde ihmal edilen ayrıntılara dikkat çekilmiştir.

\section{SU BİLANÇOLARI TARTIŞMALARI}

Yeraltı suyu bütçesini efsane ilan eden ve "Beslenimin bilinmesi, sürdürülebilir bir yeraltı suyu gelişiminin belirlenmesinde önemlidir." görüşünün doğru olmadığını açıklayan çalışmalarda verilen dairesel ada örneği Şekil 2'de görülmektedir (Bredehoeft vd., 1982; Bredehoeft, 1997; 2002) 

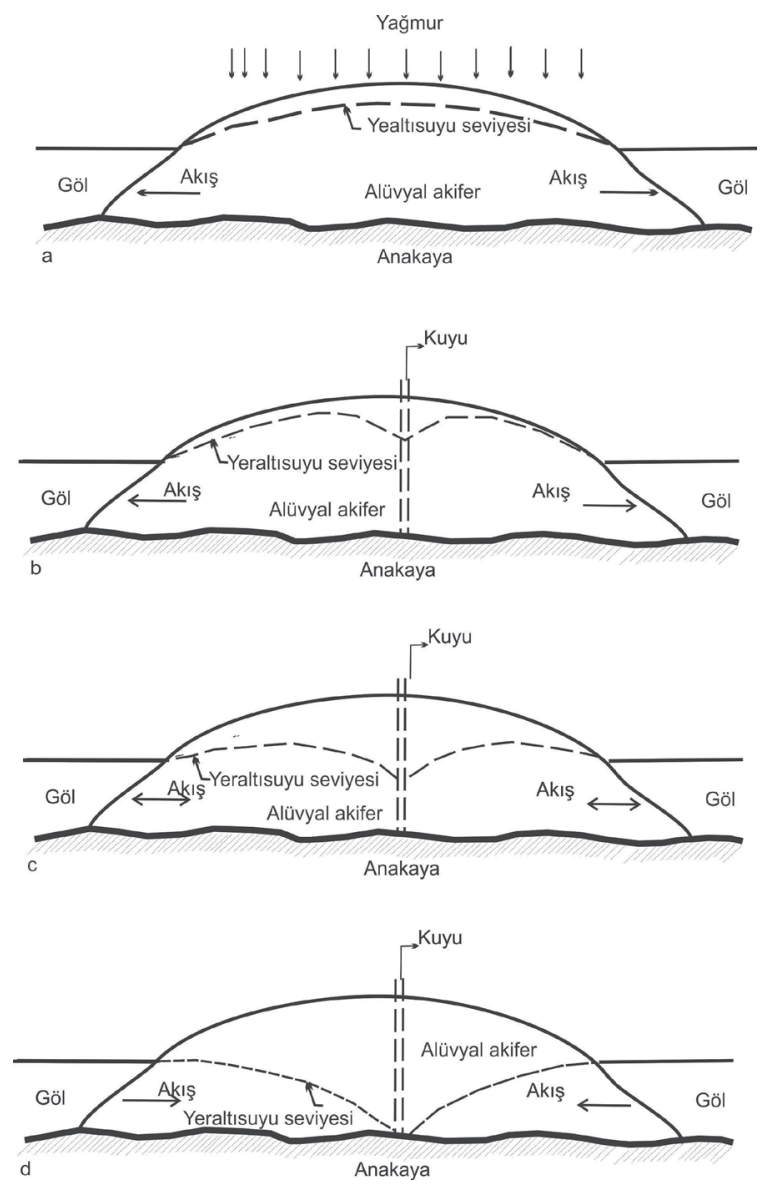

Şekil 2. Göllerle çevrili dairesel ada akiferinin çeşitli durumları a) Başlangıç b) Kuyularla yeraltı suyu çekimi c) Yeraltı suyu seviyesinin göl seviyesine inmesi d) Gölün akiferi beslemesi (Bredehoeft, 2002).

Figure 2. Schematic cross section of the island aquifer system, which illustrates that a) Virgin conditions b) The cone of depression soon after pumping has begun c) Groundwater level descending to the lake level d) Lake recharges aquifer (Bredehoeft, 2002).

Doğal şartlarda, yani yeraltı suyu kullanılmaya başlanmadan önce, dengeli akım koşullarında doğal beslenim (R) doğal boşalıma (D) eşittir (Şekil 2 a).

$\mathrm{R}-\mathrm{D}=0$
Sistemden su çekilmeye başlanmasından sonra koşullar aşağıdaki ifadeye dönüşür (Şekil $2 b, c)$

$(\mathrm{R}+\Delta \mathrm{R})-(\mathrm{D}+\Delta \mathrm{D})-\mathrm{Q}+\mathrm{dV} / \mathrm{dt}=0$

$\Delta \mathrm{R}=$ Beslenimdeki değişim

$\Delta \mathrm{D}=$ Boşalımdaki değişim

$\mathrm{Q}=$ Toplam çekim

$\mathrm{dV} / \mathrm{dt}=$ Depolanan su miktarındaki değişim ve (2) no'lu denklemden

$\Delta \mathrm{R}-\Delta \mathrm{D}-\mathrm{Q}+\mathrm{dV} / \mathrm{dt}=0 \quad$ (3) elde edilir.

Beslenimdeki artış, boşalımdan alıkonan sularla dengeye ulaşan akiferdeki değişim rezervden eksilen sudur (Şekil 2d).

$\Delta \mathrm{R}-\Delta \mathrm{D}-\mathrm{Q}=\mathrm{dV} / \mathrm{dt}$

Sürdürülebilir yeraltı suyu üretimi için rezervdeki değişimin 0 olması istenir.

$\mathrm{dV} / \mathrm{dt}=0$

$\mathrm{Bu}$ durumda $\Delta \mathrm{R}-\Delta \mathrm{D}-\mathrm{Q}=0$ ve

$\Delta \mathrm{R}-\Delta \mathrm{D}=\mathrm{Q}$

Çoğu zaman akiferlerde buharlaşmanın azaltılmasına bağlı beslenim artışı gerçekleştirilemediği için yeraltı suyu bilançosu;

$\Delta \mathrm{D}=\mathrm{Q}$

Yani "pompajla çekilen su, boşalımdan alıkonan sulardır" denilerek beslenim göz ardı edilmiştir.

Ancak doğada, dairesel ada örneğindeki gibi dengeli akım koşulları çoğu zaman sağlanmamıştır. Özellikle karstik akiferlerde yeraltı suyu boşalımı beslenimden fazla hesaplanmaktadır (Demiroğlu vd., 2011; Eris ve Wittenberg, 2015). Bu anlamda sisteme giren su miktarının çok üstünde boşalımı olan havzalarda, boşalımdan alıkonan suları dikkate almak, 
yalnız beslenimi dikkate alan yaklaşım kadar eksiktir. Bredehoeft (2002), doğal beslenimin bilinmesinin önemsiz olduğuna ilişkin sonuca, denklemlerin anlamlarının ötesinde varmıştır (Zhou, 2009).

Matematiksel modeller, gerçek hidrojeolojik sistemin belirli varsayımlar ile sadeleştirilerek matematiksel fonksiyon ve eşitlikler ile ifadesidir. Gerçek sistem (doğa) son derece karmaşık bir yapıya sahiptir ve günümüzde doğal süreçleri tüm yönleri ile matematiksel eşitlikler ile ifade etmek mümkün değildir. Bu nedenle sistemin ilgilenilen süreçlerini öne çıkaran, diğer süreçleri ise arka plana iten ya da yok sayan sadeleştirmelere gerek duyulmaktadır. Bu nedenle aynı sistemin birden fazla model ile ifadesi mümkündür (Tezcan, 1993; 2002). Her akiferin koşulları farklıdır. Akiferlerden farklı yıllarda hatta farklı iklim koşullarında sisteme giren değişik yaşlardaki sular boşalmakta ve akiferin özelliklerine ve zamana bağlı dengeler gelişmektedir. Fosil suların depolandığı akiferlerde bu denge hiç bir zaman gerçekleşmeyecektir. Yani R - D = 0 (1) teorik olarak sıfirdır. Dairesel ada örneğinde olduğu gibi modeller, sınır koşulları kesin olarak belirlenmiş sistemleri temsil eder. Kalibrasyon yapılan dönemlerde model ve modellenen akifer sisteminin benzer tepkileri verdiği hesaplansa da bölgesel değişimlerden ne ölçüde etkileneceğini hesaplamak oldukça karmaşık olduğu için sonraki yıllarda hiç beklenmeyen sonuçlarla karşılaşmak mümkündür. Özellikle yeraltı suyu modelleme çalışmaları; yerine getiremediği hayali vaatlerinden dolayı çoğu zaman test edilemeyen, kendi kendini destekleyen sanayi haline gelmiştir (Voss, 2011). Modellerin kalibrasyonu ve sonuçlarının başarısının kontrolü ancak etkin yeraltı suları izleme programları ve ağlarının oluşturulması ile gerçekleşebilir (Korzoun vd., 1978 ).
Emniyetli çekim miktarının belirlenmesinde beslenimin etkisinin hidrojeolojik modellerle gösterilmesine benzer bir yaklaşımla Tufan (2007), Bakırköy Havzası'nı modellemiştir. Çalışmasında İstanbul'un batısında Bakırköy ilçe sınırları içerisinde yer alan Bakırköy Havzası'nın mevcut durumu ve son 45 y1l içinde göstermiş olduğu değişimleri gösteren 3 boyutlu (3D) modeli oluşturulmuştur. Yaklaşı $15 \mathrm{~km}^{2}$ alanı kaplayan akifer (Üst Miyosen yaşlı Çukurçeşme formasyonu) kum ve çakıllardan oluşmuştur. Altta yerel boşluklu Eosen Kırklareli kireçtaş1 ve üstte Miyosen kil ve marnlar (Güngören formasyonu) ile sınırlı basınçlı bir akiferdir (Şekil 3).

Günümüzde kuru olan çalışma alanının yeraltı suyu modeli 1981 yılı ölçümlerinden yararlanılarak oluşturulmuştur. Model oluşturulduktan sonra, akiferin eski haline getirilebilmesi için gerekli beslenme miktarı, 1981 y1lından günümüze kadar olan süredeki değişimi için yapılmış olan çekim miktarı ve beslenmenin bu değişimler üzerindeki etkisi, oluşturulan farklı simülasyonlarla ortaya konulmuştur.

1960 y1lında akiferin tamamının yeraltı suyu ile dolu olduğu ve yeraltı su seviyesinin -10 $\mathrm{m}$ ile $+0,3 \mathrm{~m}$ arasında değiştiği bilinmektedir. 1981 yılından 1960 yılındaki duruma yeniden gelebilmek için akiferin ne kadar beslenmesi gerektiği birinci simülasyonda denenmiştir. Günümüzde kuyulardaki su seviyesi derinliği 120-130 metre civarındadır, bu da Çukurçeşme akiferinin hemen hemen kuru olduğunu göstermektedir. 1981 yılından bugünkü duruma gelirken akiferden ne kadar su çekimi yapıldığ 1 ikinci simülasyonda belirlenmiştir. 

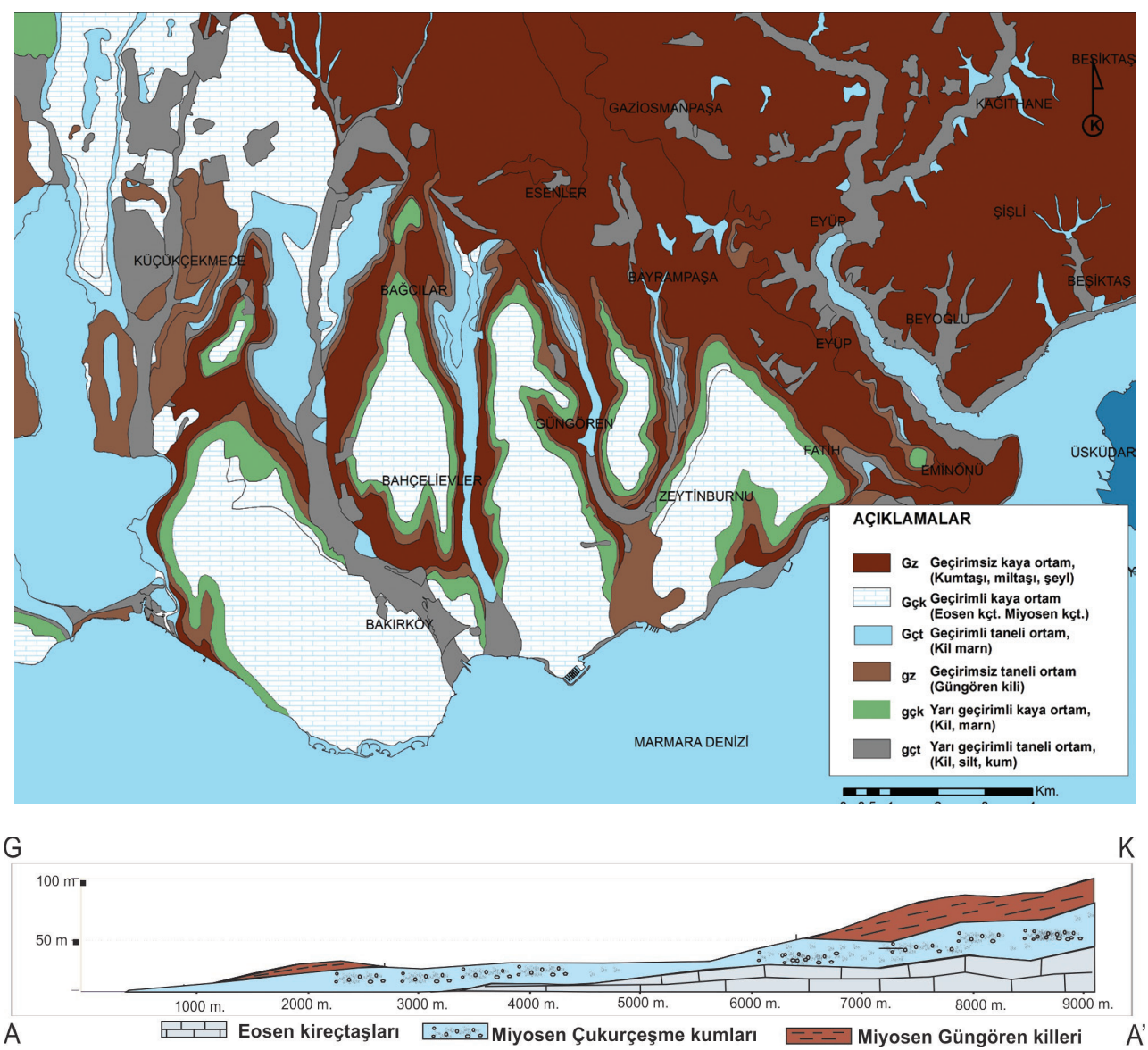

Şekil 3. Haliç Küçükçekmece arası hidrojeoloji haritası (Özgül, 2006 ve Öztaş, 2008'den değiştirilerek hazırlanmıştır).

Figure 3. Hydrogeological map in the region between Haliç (Golden Horn) and Küçükçekmece (revised from Özgül, 2006 and Öztaş, 2008).

Üçüncü simülasyonda, birinci simülasyonda olduğu gibi su seviyesini 1981 y1lındakinden 1960 yılındaki seviyeye getirebilmek için kuyularda yapılan su basımı işlemi sırasında, doğal beslenme ihmal edilerek beslenmenin ne derece etkili olduğu ortaya konulmuştur. Doğal beslenimin, yeralt1 suyu seviyesini sadece 0.0007 metre gibi önemsenmeyecek kadar küçük bir miktar değiştirdiği belirlenmiştir. Burada 1960'l1 yıllara kadar ne kadar sürede depolandığg 1 bilinmeyen yeraltı suyunda 50 yılda oluşturulan $41 * 10^{6} \mathrm{~m}^{3}$ eksilmeyle, y1llik beslenim miktar kıyaslanmıştır. Doğal olarak etkisi ihmal edilecek kadar az olacaktır.

\section{DEĞERLENDİRMELER}

Theis (1940) öncesinde toplumsal bilince yerleşen "beslenimin ve boşalımın dengede olduğu ve doğal beslenim kadar ya da doğal beslenimin \%70'i kadar pompaj yapıldığ 1 zaman doğal dengenin korunacağı" yaklaşımı hatalıdır. Pompajla çekilen su mutlaka bir yerlerden eksilmeye karşılık gelecektir. Pompaj suyunun kaynağı, (1) yeraltı suyu sistemine giren daha fazla su (artan beslenim), (2) sistemden çıkan suyun alıkonması (boşalımın azalması), (3) sistemde depolanan suyun tüketilmesi veya bu üçünün birleşimidir (Theis, 1940; Lohman vd., 
Demiroğlu

1972; Alley vd., 1999; Bredehoeft vd., 1982; Galloway vd., 2001; Yazıcıgil, 2006; Henriksen ve Refsgaard, 2013).

Beslenimi dikkate almayıp sadece boşalımı dikkate alan yaklaşım da benzer şekilde eksiktir. Baz akışı yani yeraltı suyu boşalımı yüksek olan havzalarda boşalım, beslenimden çok daha fazla olmaktadır. Yıllık beslenimler, çok uzun yıllarda depolanan sularla kıyaslandığında önemsiz görülebilir. Nitekim Devlin ve Sophocleous (2005), sürdürülebilir pompajla sürdürülebilir yeraltı suyu yönetimini birbirinden ayırarak beslenimin sürdürülebilirliğin bir fonksiyonu olduğunu ve sürdürülebilir pompaj oranlarının beslenim bilinmeden tahmin edilebileceği gerçeğine rağmen sürdürülebilir yeraltı suyu yönetiminde beslenimin önemli olduğunu göstermişlerdir. Doğal koşullar altında, yeraltı suyu sistemleri uzun vadeli ortalama beslenimin uzun vadeli ortalama boşalıma eşit olduğu dinamik denge koşullarına sahiptir. Bir akiferden yeraltı suyunun pompalanması her zaman yeraltı suyu seviyesinin azalmasina neden olacaktır (Sophocleous, 2000). Bu, sularin besleniminin arttırılmasını ve boşalımdan alıkonmasını sağlayacaktır. Pompalama oranı alıkonan sulardan daha büyük olduğunda, yeraltı su seviyeleri sürekli olarak düşecek ve yeraltı suyu eninde sonunda tükenecektir ( Aeschbach-Hertig ve Gleeson, 2012).

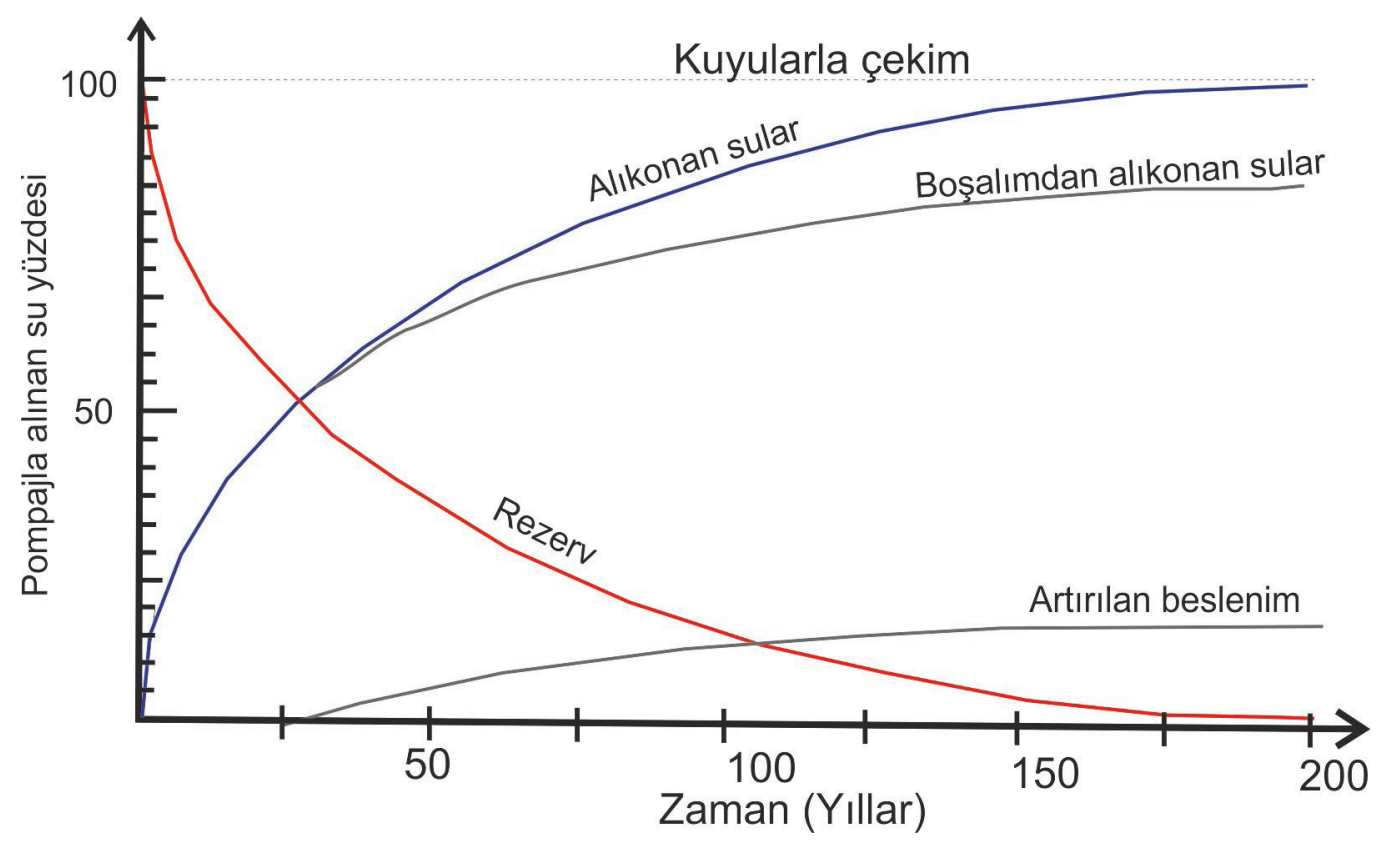

Şekil 4. Doğal şartlarda bir akiferden yeraltı suyu çekimi başladığında ne olur? (Bjerre, 2012; Henriksen ve Refsgaard, 2013). Figure 4. What happens when groundwater is abstracted under natural conditions? (Bjerre, 2012; Henriksen and Refsgaard, 2013). 
Şekil 4'te “alıkonan suların” önemi gösterilmektedir. $\mathrm{t}=0$ anında sabit bir yeraltı suyu çekimi başlatılır. Bu, akiferin var olan dengesini etkiler. Yeraltı suyu beslenimi zamanla artar. Boşalma (nehir akışı) azalır. Yeraltı suyu rezervi azalır. Başlangıç döneminde, çekim rezervi azaltır, ancak daha sonra yeni denge oluşur. Belli bir aşamada beslenim artışı ve boşalımdan alıkonan sularla rezervden tüketim durabilir.

Bazı akiferlerde alıkonan sularla dengeli akım koşulları kısa sürede gerçekleşirken, bazılarında dengeli akım koşulları sağlanıncaya kadar tükenebilmektedir. Rezervden tüketilen suların geri dönüşümü çoğu zaman mümkün olmamaktadır.

Yeraltı su seviyesi yükselimlerinin taşkınlara önemli etkisi olmaktadır (Galloway ve Ingebritsen, 2001; Demiroglu, 2016). Komşu havzalardan büyük miktarlarda su getirilen İstanbul'un önemli akiferlerinde su bütçesi değişiklikleri takip edilmemektedir. Yeraltı sularının sel felaketlerine etkisi değerlendirilmemektedir. Ayamama Deresi islah çalışmaları Ayamama Deresi ile yeraltı suyu ilişkisi belirlenmeden tamamlanmıştır.

Yeraltı suyu seviye düşümleri açısından bakıldığında boşalımdan alıkonan sular, derelerin, kaynakların kurumasına, kıyı ekosistemlerinin ve sulak alanların kaybedilmesine neden olabilmektedir. Bugünkü çekim miktarlarının etkilerinin uzun vadede ne olacağının hesaplanması gerekmektedir.

Dumlu (2005), emniyetli çekimin su kalitesini bozmadan en uygun düşümle bir dinamik seviye belirlenmesi olduğunu ifade etmiştir. $\mathrm{Bu}$ seviyenin, yağışın uzun yıllar ortalamasına eşit olduğu bir sürenin sonunda değişmemesi durumunda, emniyetli çekim olarak dikkate alınabileceğini savunmuştur. Emniyetli çekimin, her akifer için o akiferin hidrodinamik özelliklerine göre, uzun süreli gözlemler sonucu belirlenebileceğini vurgulamıştır.

\section{SONUÇLAR}

Sürdürülebilir yeraltı suları çekiminde kuyu yerleri boşalımdan alıkonan ve beslenim artışlarını dikkate alan yaklaşımla seçilmeli, her sene çekilen yeraltı suyu miktarıyla yıllık beslenim ve boşalım miktarı arasında uzun süreli bir denge kurulmalıdır. Yeraltı suyu kullanımında emniyetli çekim, her akifer için ayrı hidrodinamik özelliklere göre belirlenmelidir.

Yeraltı su seviyesi düşümlerinin ve yükselimlerinin olası olumsuz etkileri (Tuzlu su dalımı, çökmeler, sellenme ve sanat yapılarına etkileri, vb), su kalitesindeki değişimler ve boşalımdan alıkonan suların uzun vadede çevreye etkileri modelleme çalışmalarıyla değerlendirilmelidir. Yeraltı suları izleme programları ve ağları ile model sonuçları takip edilmelidir. Bu değişimlere bağlı olarak emniyetli çekim miktarları güncellenmelidir.

\section{KATKI BELİRTME}

Yazar, bu makalenin hazırlanmasina ve düzeltilmesine katkıda bulunan Doç. Dr. H. Tolga Yalçın'a teşekkürlerini sunar.

\section{KAYNAKLAR}

Aeschback-Hertig, W., Gleeson, T., 2012. Regional strategies for the accelerating global problem of groundwater depletion. Nature Geoscience, 5 (12), 853-861.

Aksever (Seyman), F., 2012. Yeraltı suyu bilançosu nedir?, SDUGEO ISSN $1309-6656,3 / 1$, s. 3743. (Online: www.geo.sdu.edu.tr). 
Demiroğlu

Alley, W. M., Reilly T. E., Franke O. L., 1999. Sustainability of ground-water resources. U.S. Geological Survey Circular 1186. Reston, Virginia: USGS. (on line:http://pubs.usgs.gov/ circ/circ1186)

Alley, W. M., Leake S. A., 2004. The journey from safe yield to sustainability. Ground Water, 42 (1), 12-16.

Bjerre, T. K., 2012. Bæredygtig vandindvinding hvad er det? ATV vintermøde.

Bredehoeft, J. D., Papadopulos S. S., Cooper H. H., 1982. Groundwater: The water-budget myth. In Scientific Basis of Water-Resource Management. 51-57. Washington, DC: National Academy. (Online: http://aquadoc.typepad. com/waterwired/ files/water_budget_myth bredehoeft_et_al..pdf)

Bredehoeft, J. D., 1997. Safe yield and the water budget myth. Ground Water, 35 (6), 929.

Bredehoeft, J. D., 2002. The water budget myth revisited: Why hydrogeologists model. Ground Water 40 (4), 340-5.

Bredehoeft J., Durbin T., 2009. Ground water development-the time to full capture problem. Groundwater, 47 (4), 506-514.

Demiroğlu, M., Orgun, Y., Yaltırak, C., 2011. Hydrogeology and hydrogeochemistry of Gunyuzu semi-arid basin. Environmental Earth Sciences, 64 (5), 1433-1443.

Demiroğlu, M., 2016. Classification of karst springs for flash-flood-prone areas in western Turkey. Natural Hazards and Earth System Sciences, 16, 1473-1486.

Devlin, J. F., Sophocleous, M., 2005. The persistence of the water budget myth and its relationship to sustainability. Hydrogeology Journal, 13 (4), 549-554.

Dumlu, O., 2005. Hidrojeolojide tartışmalı konular ve görüşler (1. Bask1). Maden Mühendisleri Odası, İstanbul, $124 \mathrm{~s}$.

Eris, E., Wittenberg, H., 2015. Estimation of baseflow and water transfer in karst catchments in Mediterranean Turkey by nonlinear recession analysis. Journal of Hydrology, 530, 500-507.
Freeze, R. A., Cherry, J. A., 1979. Groundwater. Prentice-Hall, Inc., Englewood Cliffs, New Jersey, $604 \mathrm{p}$.

Galloway, D., Jones D. R., Ingebritsen, S. E., 2001. Land subsidence in the United States. U.S. Geological Survey Circular 1182, Denver, Colorado, 175 p. (http://pubs.usgs.gov/circ/ circ1182).

Henriksen, H. J., Refsgaard, J. C., 2013. Sustainable groundwater abstraction, review report file://E:/ Recharge\%20ve\%20emniyetli\%20verim/ denmark\%20report_2013_30.pdf).

Korzoun, V. I., Sokolov, A. A., Budyko, M. I., Voskresensky, K. P., Kalinin, G. P., 1978. World water balance and water resources of the earth. Studies and Reports in Hydrology (UNESCO), no. 25 / United Nations Educational, Scientific and Cultural Organization, 75. Paris (France); International Hydrological Decade, Moscow (USSR). USSR National Committee , 1978 , 663 p.

Lee C. H., 1915. The determination of safe yield of underground reservoirs of the closed basin type. Transactions of the American Society of Civil Engineers, 78, 148-151.

L'vovich, M. I., 1979. World water resources and their future. Translation of the original Russian edition (1974), American Geophysical Union, Washington, D.C.

Lohman, S.W., Bennett, R. R., Brown, R. H., Cooper, H. H., Drescher, W. J., Ferris, J. G., Johnson, A. I.,. McGuiness, C. L., Piper, A. M., Rorabaugh, M. I., Stallman, R. W., Theis, C.V., 1972. Definitions of selected ground-water termsRevisions and conceptual refinements. U.S. Geological Survey Water-Supply Paper 1988. Reston, Virginia: USGS

Muller, D. A., Price, R. D., 1979. Ground-water availability in Texas, estimates and projections through 2030: Texas Department of Water Resources Report 238, 77 p.

Özgül, N., 2006. İstanbul Jeolojisi. İstanbul Büyükşehir Belediesi Planlama ve İmar Dairesi Başkanlığı Şehir Planlama Müdürlüğü, İstanbul 
Büyükșehir Nazım İmar Planı Analitik Etüdler İşi, 98 s, İstanbul, (Yayınlanmamış Proje).

Öztaş, T., 2008. İstanbul'un su politikası sempozyumu, Bildiriler Kitab1, İstanbul, 78-106.

Ponce, V. M., Pandey R. P., Ercan, S., 2000. Characterization of drought across climatic spectrum. Journal of Hydrologic Engineering, ASCE, 5/2 222-224.

Sophocleous, M,. 2000. From safe yield to sustainable development of water resources - The Kansas experience. Journal of Hydrology, 235 (1-2), 27 43.

T.C. Resmi Gazete, 2014. Yüzeysel suları ve yeraltı sularının izlenmesine dair yönetmelik, 28910.

Tezcan, L., 1993. Karst akifer sistemlerinin trityum izotopu yardımıyla matematiksel modellemesi. Hacettepe Üniversitesi Fen Bilimleri Enstitüsü, Ankara, Doktora Tezi $121 \mathrm{~s}$.

Tezcan, L., 2002. New isotopes and their uses in hydrological studies. 1. Symposium on the use of isotope techniques in national hydrology, Adana.
Theis, C. V., 1940. The source of water derived from wells-Essential factors controlling the response of an aquifer to development. Civil Engineering, 10, 277-280.

Todd, D. K. 1959. Groundwater hydrology. John Wily \& Sons, Inc., New York, 336 p.

Tufan, S., 2007, Bakırköy Havzasının bilgisayar ortamında modellenmesi, İTÜ, Fen bilimleri Enstitüsü,Yüksek Lisans tezi, Maslak $90 \mathrm{~s}$.

Voss, C. I., 2011. Editor's message: Groundwater modeling fantasies - part 1, adrift in the details. Hydrogeology Journal, 19, 1281-128.

Yazıcıgil, H., 2006. Sürdürülebilir ve Emniyetli Akifer Verimleri. 59. Türkiye Jeoloji Kurultayı Bildiri Özleri Kitabı, 101-103.

Zhou, Y., 2009. A critical review of groundwater budget myth, safe yield and sustainability. Journal of Hydrology, 370, 207-213. 